\title{
Ag/Nd2o3-Zno Nanocomposite: Visible Active Efficient Photocatalytic Degradation of Methylene Blue and Its Antibacterial Activity
}

\author{
Arunpandian M., Selvakumar K., Nagarajan E. R., Arunachalam S.
}

\begin{abstract}
In this scenario, the photocatalyst $\mathrm{Ag} / \mathrm{Nd} 2 \mathrm{O3}-\mathrm{ZnO}$ (ANZ) are prepared under hydrothermal method and the complete build was confirmed by X-ray diffractometer, Scanning electron microscope with EDX spectroscopy. From the results, the crystalline structure was confirmed by PXRD spectroscopy. And in the SEM, spherical with sponge-like clustered morphology structure was shown and the presenting elements are confirmed by EDX spectroscopy. The suitable light needed for the degradation was selected by DRS-UV spectroscopy. The dye Methylene blue $(\mathrm{MB})$ is degraded under visible light within 30 minutes with the efficiency of $98.12 \%$. The catalyst is further analysed optimized concentration, different catalyst loading, and the catalyst efficiency was analyzed by reusability study. From the recyclability, the catalyst is stable up to the fifth run. Besides, the photocatalytic study the catalyst is analysed antibacterial activity. For the results, the Bacillus bacteria having more antibacterial activity compared to E.coli bacteria.
\end{abstract}

Keywords: Photocatalyst, Methylene blue, Rare earth metal, visible light, antibacterial activity

\section{INTRODUCTION}

In this modern world, day by day the uses of cosmetics, pharmaceutical drugs, colouring agents (dyes), chemicals are increased by human beings. Over two thirds in the world, water have circulated the earth. The overall water resources are polluted by waste drugs, industrial dyes, and other chemical compositions. Besides, it affected by a human beings and animals [1]. The polluted water is not completely removed by treating of a conventional, physical and chemical method [2]. Advanced Oxidation Processes (AOPs) comprise a series of methods such as ozonation, photocatalysis, electrochemical oxidation, Fenton and Fenton-like processes, etc., but in the above advanced oxidation process, including photocatalytic degradation process, can be done to remove waste from the pollutant water. Photocatalytic degradation has been great environmental remediation for the pollutant

Revised Manuscript Received on December 15, 2019

* Correspondence Author

M. Arunpandian, Nanomaterials Laboratory, Department of Chemistry, International Research Centre, Kalasalingam Academy of Research and Education (Deemed to be University), Krishnankoil - 626126, India. Email: arunpandiantt126@gmail.com

K. Selvakumar, Nanomaterials Laboratory, Department of Chemistry, International Research Centre, Kalasalingam Academy of Research and Education (Deemed to be University), Krishnankoil - 626126, India. Email: selvachemistk@gmail.com

E. R. Nagarajan, Nanomaterials Laboratory, Department of Chemistry, International Research Centre, Kalasalingam Academy of Research and Education (Deemed to be University), Krishnankoil - 626126, India. Email: nagarajanklu@gmail.com

S. Arunachalam*, Nanomaterials Laboratory, Department of Chemistry, International Research Centre, Kalasalingam Academy of Research and Education (Deemed to be University), Krishnankoil - 626126, India. Email: drarunachalam.s@gmail.com removal from the wastewater. In this work Methylene blue (MB) dye was degraded under AZG nanocomposite. The dye $\mathrm{MB}$ is a major ingredient to polluted water from the dyeing and printing textile industries and it has an intensely coloured compound [3].

From this nanocomposite, $\mathrm{Nd} 2 \mathrm{O} 3$ having a hexagonal crystal lattice structure and has a good electric and catalytic behaviour. It is mostly used to study the luminescent, photonic and protective coating applications [4-7]. By the quantum confinement effects $\mathrm{ZnO}$ particles having some optical properties [8]. Besides, the applications of $\mathrm{ZnO}$ are catalysts, transistors in Besides, the applications of $\mathrm{ZnO}$ are catalysts, transistors in a transparent thin film, surface wave acoustic devices, cancer-detecting biosensors, degradation of dyes, pharmaceuticals and other organic compounds, etc., [9-10]. The Ag-doped $\mathrm{Nd} 2 \mathrm{O} 3-\mathrm{ZnO}$ nanoparticles are synthesis by hydrothermal method and it is having a good surface area, non-toxicity, good ability and high efficient in photocatalytic degradation process and it is confirmed by the following characterization techniques, like Scanning electron microscope (SEM) with EDX spectroscopy, X-Ray diffractometer spectroscopy and DRS- UV spectroscopy. The degradation of pollutant is detected by UV-Visible spectroscopy technique. By the $\mathrm{Ag} / \mathrm{Nd} 2 \mathrm{O} 3-\mathrm{ZnO}$ catalyst, the pollutant $(\mathrm{MB})$ is converted into $\mathrm{CO} 2$, water and some mineral acids.

\section{ANTIBACTERIAL ACTIVITY TEST BY DISC DIFFUSION METHOD}

The biological study (antibacterial activity) of the synthesized material was performed by disc diffusion method. The test was used to measure the sensitivity of the test material in terms of diameter of clear zone of inhibition in the disc. Lucia agar plates were prepared and overnight culture of Bacillus and E.coli $(100 \mu \mathrm{l})$ were swabbed on the surface of Luria-Bertani medium (Becton Dickinson). The disc is commercially prepared which can impregnate with a standard concentration of nanoparticles and slightly pressed the agar surface. The plates were incubated at $37^{\circ} \mathrm{C}$ for 24 hours for the diffusion of the sample into the agar medium. The pharmaceutical material (streptomycin) and the distilled water were used as a positive and the negative control for the bacterial system. The zone of Inhibition formed around the well was measured the biological activity [11]. 


\section{Ag/Nd2o3-Zno Nanocomposite: Visible Active Efficient Photocatalytic Degradation of Methylene Blue and Its Antibacterial Activity}

\section{MATERIALS AND METHODS}

\section{A. Materials and characterization}

Silver nitrate, Neodymium acetate, Zinc acetate raw materials are purchased from Sigma Aldrich. And Oxalic acid, Sodium hydroxide, $\mathrm{C} 4 \mathrm{H} 6 \mathrm{O} 4 \mathrm{Zn} \cdot 2 \mathrm{H} 2 \mathrm{O}$, Methylene blue (Merck Chemicals, India) are the other raw materials. All the solutions are prepared to use distilled water. The Scanning electron microscope with a model (EVO-80, CARL ZEISS) and the (EDX) spectroscopy (AMETEK-EDAX (Z2e Analyzer)) is used to predict surface morphology and the presence of elements to the nanocomposite. The crystalline structure of the sample was analyzed by powder X-ray diffraction (PXRD) (Shimadzu XRD-6000 X-ray diffractometer $(\mathrm{Cu} \mathrm{K \alpha}$ source)). The bandgap was analyzed by UV-Vis diffuse reflection spectroscopy (DRS) was performed on a Shimadzu UV-2450 spectrophotometer. The UV-visible spectroscopy with the model Shimadzu UV-1800 spectrophotometer is used to analyze the degradation efficiency of the collecting photocatalytic degradation samples.

\section{B. Preparation of Catalysts Synthesize of Nd2O3-ZnO (NOZ)}

In $100 \mathrm{~mL}$ of deionized water $\mathrm{Nd}(\mathrm{CH} 3 \mathrm{CO} 2) 3.6 \mathrm{H} 2 \mathrm{O}$ $(6 \mathrm{mmol})$ solution was dissolved at room temperature. The $\mathrm{pH}$ of the solution was adjusted to 10 with $\mathrm{NaOH}$ for the complete precipitation. From the suspension mixture $100 \mathrm{~mL}$ $0.4 \mathrm{M} \mathrm{Zn}(\mathrm{CH} 3 \mathrm{CO} 2) 2 \cdot 2 \mathrm{H} 2 \mathrm{O}$ solution was added and stirred for $30 \mathrm{~min} .100 \mathrm{~mL}$ of dissolved oxalic acid $(0.6 \mathrm{M})$ was added to the above suspension until dropwise and stirred for 4 $\mathrm{h}$ to the complete precipitation. After completion, the reaction the suspension mixer was transferred in Teflon lined stainless steel autoclave at $115^{\circ} \mathrm{C}$ for $12 \mathrm{~h}$. The hydrothermally treated samples were dried in an oven at $80^{\circ} \mathrm{C}$ for $12 \mathrm{~h}$ and annealed at $650^{\circ} \mathrm{C}$ for $12 \mathrm{~h}$ in a furnace.

\section{Synthesize of Ag/Nd2O3-ZnO (AOZ)}

The catalyst $\mathrm{NOZ}(1 \mathrm{mmol})$ and silver nitrate $(0.5 \mathrm{mmol})$ are dissolved in $100 \mathrm{ml}$ of distilled water with a Stoichiometry ratio, then these solutions the reducing agent solution form of sodium borohydride are added with drop wisely. And subsequently, the solution was allowed to cool at room temperature. After some time the precipitate was formed. The formed precipitate was collected by filtration and washed with water and ethanol. And the precipitate was dried in a vacuum oven at $60^{\circ} \mathrm{C}$ at overnight. Finally, the dry samples are annealed at $650^{\circ} \mathrm{C}$ for $8 \mathrm{~h}$ in a furnace.

\section{Photocatalytic experiments}

In the visible light degradation, Heber multi-lamp as a (tungsten lamp as a light source and the intensity is $150 \mathrm{~mW} / \mathrm{cm}^{-2}$ ) photoreactor for the degradation of MB under visible light $(\lambda>400 \mathrm{~nm})$ irradiation by ANZ. In $250 \mathrm{ml}$ beaker, $50 \mathrm{mg}$ of the catalyst was mixed in $100 \mathrm{ml}$ solution of MB with $30 \mu \mathrm{m}$ concentration Above dispersed mixture was agitated for $1 / 2 \mathrm{~h}$ in dark condition, to ensure the adsorption-desorption equilibrium of the reaction solution. After stirring, the dispersed solution was transferred into a $200 \mathrm{ml}$ reaction vessel. After $5 \mathrm{~min}$ time intervals, $5 \mathrm{ml}$ of the reaction solution was collected from the reaction vessel and

monitored the absorption peak of CIP at $668 \mathrm{~nm}$ using UV visible spectrometer. The catalyst was separated by an ultracentrifuge, and the catalyst is washed with de-ionized water for three times and dried at $60^{\circ} \mathrm{C}$. Finally, it is used for the reusability test. The above procedure is similar to the $\mathrm{MB}$ dye solution degradation.

\section{RESULTS AND DISCUSSIONS}

\section{A. X-Ray Diffractometer Spectroscopy}

In ANZ composite, the purity and the crystal structure of the sample are analyzed by powder X-ray diffraction (PXRD) in the range between $10-80^{\circ}$. The X-ray diffraction peaks of $\mathrm{ZnO}, \mathrm{Nd}_{2} \mathrm{O}_{3}, \mathrm{Ag} / \mathrm{Nd}_{2} \mathrm{O}_{3}-\mathrm{ZnO}$ nanocomposites are seen in Fig. 1 The observed peaks in $\mathrm{Nd}_{2} \mathrm{O}_{3}$ (JCPDS no. 74-2139) are $26.58,29.48$ and $30.52^{\circ}$ corresponds to the reflection planes (100), (002) and (011) with the structure Primitive hexagonal of $\mathrm{Nd}_{2} \mathrm{O}_{3}$ [12].

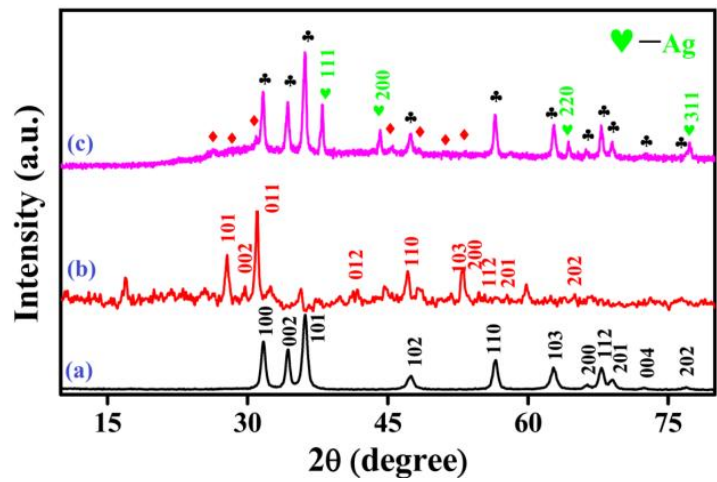

Fig. $1 \mathrm{X}$-ray diffraction for a) $\mathrm{ZnO}$, b) $\mathrm{Nd2O3}$ and c) $\mathrm{Ag} /$ Nd2O3-ZnO nanocomposite.

XRD patterns of $\mathrm{Nd} 2 \mathrm{O} 3$ shows that the material is of highly purity, because there are no impurity peaks were observed. For Ag (JCPDS - 89-3722), the intense peak present at 38.1, 44.5, 64.5 and 77.6o attributes to the plane (111), (200), (220) and (311) plane with Cubic structure system. The ZnO (JCPDS - 36-1451) diffraction peaks are observed at 31.6, 34.23, 36.18, 47.38, 56.54, 62.81, 66.22, 67.89, 69.08o respectively. In ANZ composite, the complete formation was confirmed by the presence of the diffraction peaks of $\mathrm{Ag}, \mathrm{ZnO}$, and the very low intense peak of $\mathrm{Nd} 2 \mathrm{O} 3$ are represents. The $\mathrm{Nd} 2 \mathrm{O} 3$ peaks are having visible very hard because the weight of loading of $\mathrm{Nd} 2 \mathrm{O} 3$ is very low.

\section{B. Scanning Electron Microscope and EDX Spectroscopy}

From Fig. 2 explains the morphological structure of the different nanomaterials $\mathrm{Nd} 2 \mathrm{O} 3, \mathrm{ZnO}, \mathrm{Nd} 2 \mathrm{O} 3-\mathrm{ZnO}$ and $\mathrm{Ag} /$ $\mathrm{Nd} 2 \mathrm{O} 3-\mathrm{ZnO}$ by SEM micrographs. The NO (Fig. 2b) nanoparticles having the spherical with microsponge shape structure and the $\mathrm{ZnO}$ exhibits hexagonal like clustered structural (Fig. 2a) morphology. Besides, the Nd2O3-ZnO materials having a cluster like a microsponge (Fig. 2c) structure and the $\mathrm{NO}$ are anchored in the $\mathrm{ZnO}$ surface with a good number of particles are observed. In $\mathrm{Ag} / \mathrm{Nd} 2 \mathrm{O} 3-\mathrm{ZnO}$, the Small spherical structure of silver particles (mentioned by Round mark) 
with cluster like microsponge structures are seen in Fig. 2 and it is evidenced for the confirmation of nanocomposite. From Fig. the presenting elements like $\mathrm{Ag}, \mathrm{Nd}, \mathrm{Zn}, \mathrm{O}$ and $\mathrm{C}$ in the NOZG were analyzed by EDX spectrum and it confirms the complete formation of nanocomposites.

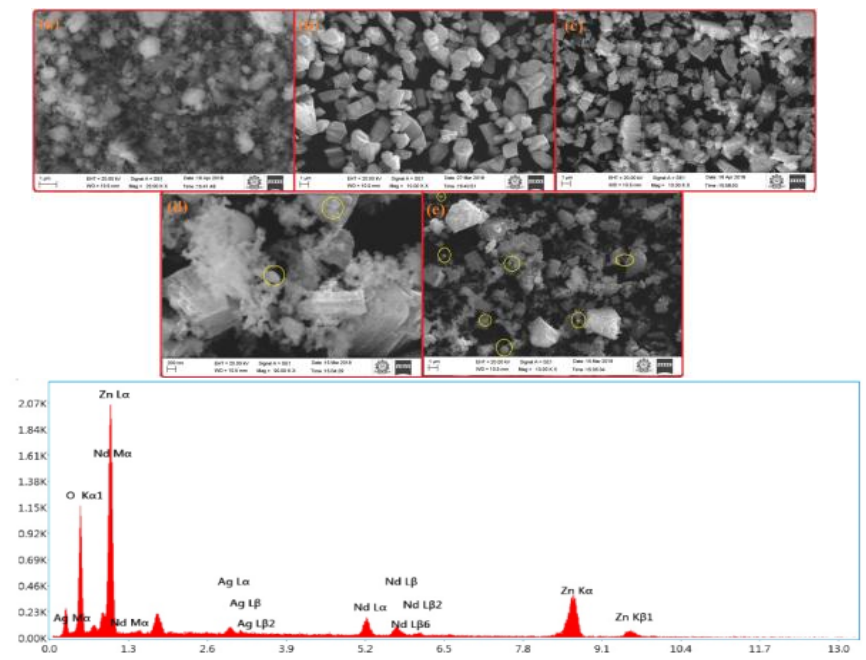

Fig. 2 SEM images of a) Nd2O3, b) ZnO, c) Nd2O3-ZnO, (d, e) Ag/ Nd2O3-ZnO at different magnification range and EDX Spectroscopy of the prepared nanocomposite

\section{DRS- UV spectroscopy}

In the photocatalytic process, the bandgap energy is to select the suitable light needed for the degradation of MB dye.

DRS-UV spectrum is predicting the band energy value. In Fig - 3 the diffuse reflectance absorption spectra of $\mathrm{NO}, \mathrm{ZnO}$, NOZ, and ANZ are shown. The bandgap value is calculated by Tauc's plot with a linear extrapolation line, where $\left((\alpha h v)^{2}\right.$ is plotted against the photon energy (hv). The bandgap value for free $\mathrm{NO}$ is $4.9 \mathrm{eV}$, for $\mathrm{ZnO} 3,23 \mathrm{eV}$, for $\mathrm{NOZ}$ is $3.21 \mathrm{eV}$ and the ANZ values are $2.8 \mathrm{eV}$. The bandgap energy decreased from $4.9 \mathrm{eV}$ to $2.8 \mathrm{eV}$. This bandgap degreasing is indicated that the ANZ photocatalyst is degraded under visible light irradiation.

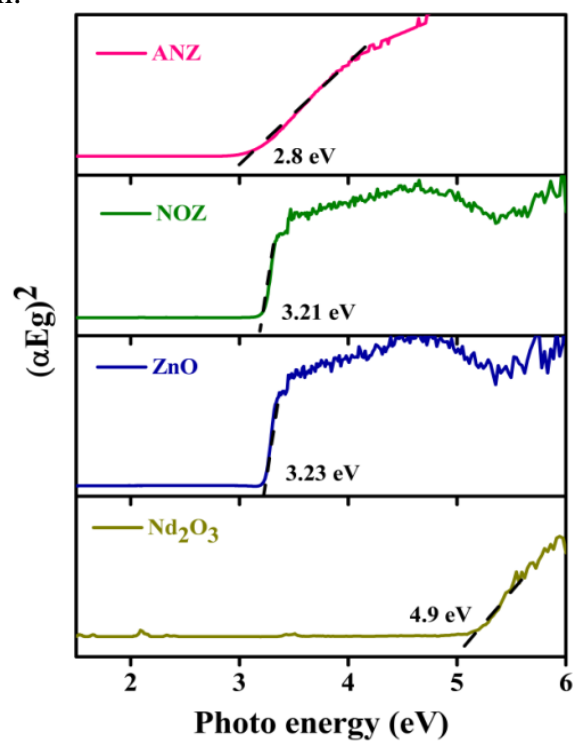

Fig. 3 DRS-UV spectrum for NO, ZnO, NOZ, and ANZ nanocomposites

\section{Antibacterial activity test}

By disc diffusion method, the antibacterial activity study was carried out under the catalyst ANZ. In ANZ composite the activity was studied against the E.Coli (Gram-negative bacteria) and Bacillus (Gram-positive bacteria) bacteria From Fig. 4 the Zone image is obtained by the ANZ composite, the positive control having a standard pharmaceutical and the negative control having distilled water. From these figures, the Zone image of two bacteria by ANZ composite, the Zone surface area of Bacillus is higher compared to the E.Coli bacteria. Therefore higher antibacterial activity of Bacillus is noticed to the study than E.Coli bacteria.

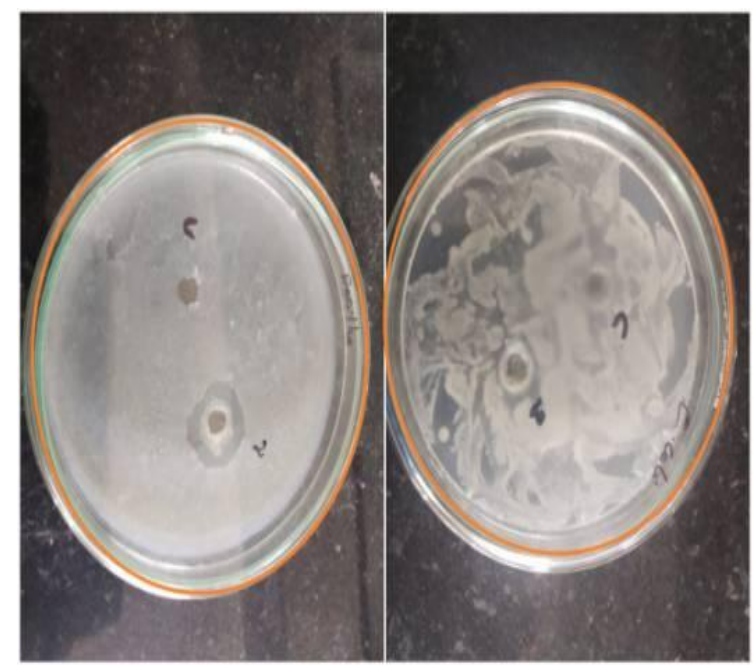

Fig. 4 Antibacterial study: The Zone image photographs of Bacillus and E.coli bacterias

\section{PHOTOCATALYTIC DEGRADATION OF MB DYE}

\section{A. The optimization of different catalyst}

The reaction conditions i.e) catalyst dosage, a suitable concentration of $\mathrm{MB}$ and degradation of different catalyst are to be optimized. From Fig. 5(a) the different catalyst $\mathrm{ZnO}, \mathrm{Nd}_{2} \mathrm{O}_{3}, \mathrm{Nd}_{2} \mathrm{O}_{3}-\mathrm{ZnO}$ and $\mathrm{Ag} / \mathrm{Nd}_{2} \mathrm{O}_{3}-\mathrm{ZnO}$ nanocomposite are degraded under visible light with the time taken 30 minutes. Compare to the different catalyst the efficiency is much more in $\mathrm{Ag} / \mathrm{Nd}_{2} \mathrm{O}_{3}-\mathrm{ZnO}$ nanocomposite compare to the others. After the (30 minutes) complete degradation the $\mathrm{C} / \mathrm{C}_{0}$ value reach almost zero. The absorption spectrum is shown in Fig. 5(b) and the absorption value is $668 \mathrm{~nm}$ respectively. 

Its Antibacterial Activity

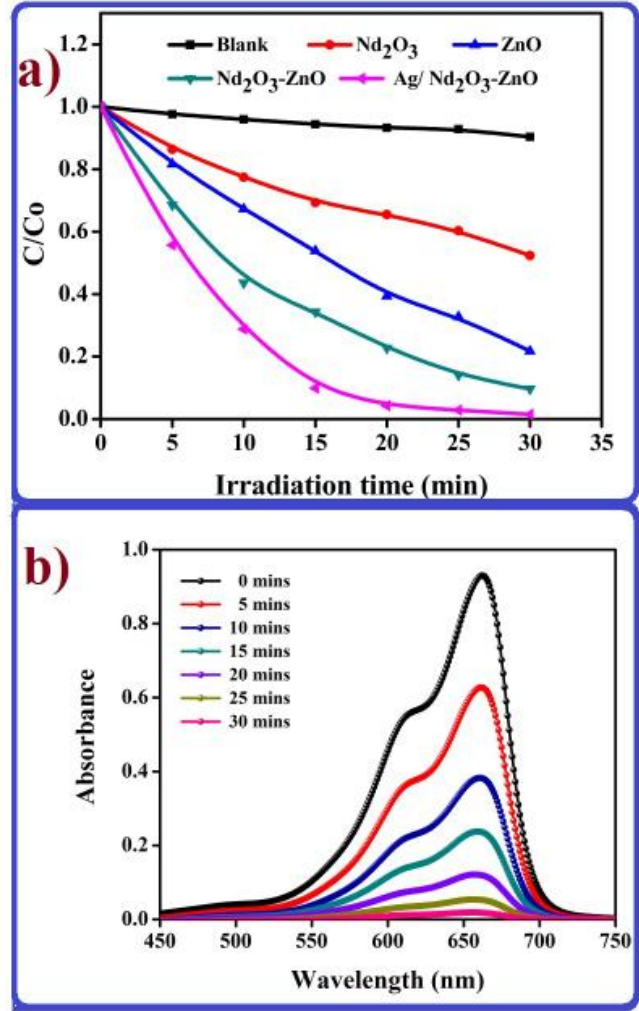

Fig. 5 a) Photocatalytic degradation of different catalyst and b) Absorption spectrum MB degradation

\section{B. The optimization of catalyst dosage}

From the degradation process, the amount of catalyst loading is very important. Fig. 6 shows the different catalyst loading (ANZ: $30-60 \mathrm{mg}$ ) of the prepared nanocomposite. The photocatalytic degradation process $50 \mathrm{mg}$ of ANZ catalyst is suitable for the degradation of MB

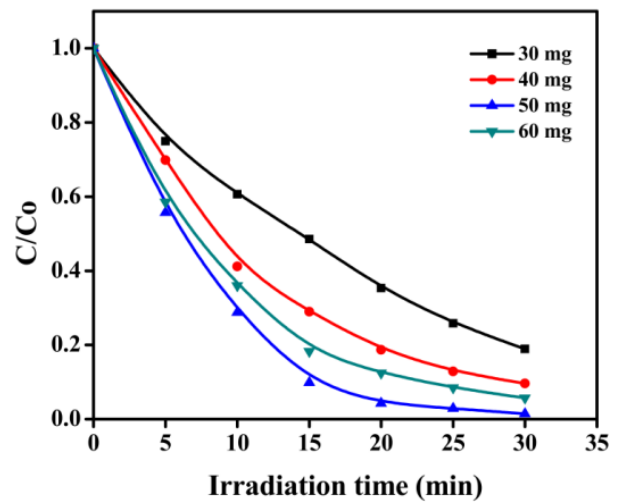

Fig. 6 Photodegradation of MB under the optimization of different catalyst dosage

At the time the degradation efficiency is increased. If used a high amount of catalyst the efficiency is decreased. Because add the high amount of catalyst to the degradation process the surface area of the degradation material is increased which leads to an increase in the reactive sites [13].

\section{Optimization of concentration}

The MB concentration was optimized between 5 $\mu \mathrm{M}$ to $15 \mu \mathrm{M}$. Because of $10 \mu \mathrm{M}$ is the best of $(\mathrm{MB})$ pollutant dye under visible light.

degradation. If the concentration of pollutant was increased, then decrease the rate of photodegradation. Therefore, the $\mathrm{MB}$ was degraded with the concentration of $10 \mu \mathrm{M}$ and it is shown in Fig. 7.

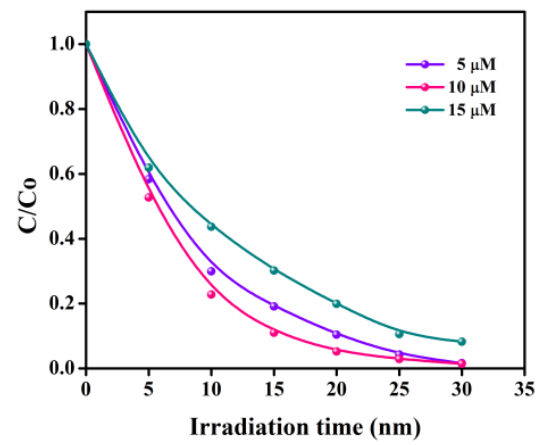

Fig. 7 Photodegradation of MB with the optimized concentration

\section{Recyclability test}

After degradation of completion, the remaining catalyst was filtered and washed with water and then dried. Further, it re-used to degrade the pollutant.

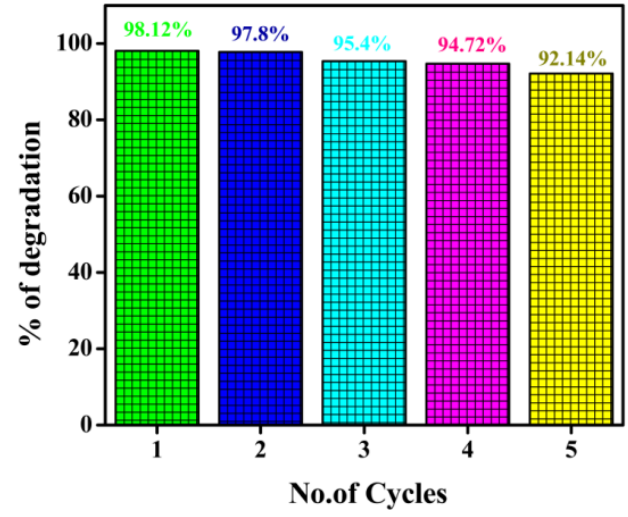

Fig. 8 Recycle efficiency of MB degradation

The catalyst was, again and again, reacted to involve the degradation under five successive runs. Fig. 8 contains the recyclability of the MB dye. In spite of this, after the fifth run, the degradation efficiency of MB by ANZ catalyst remains $92.14 \%$. The result shows the catalyst having good mechanical stability and corrosive resistance of the catalyst [14].

\section{CONCLUSION}

In summary, the ANZ nanocomposite was successfully synthesized by hydrothermal method, and detailed its spectral information's. For the results, the degradation for the MB dye under visible light irradiation is carried out by ANZ catalyst. The catalytic efficiency of ANZ is much more compared to the undoped $\mathrm{ZnO}, \mathrm{Nd}_{2} \mathrm{O}_{3}$, and NOZ nanocomposite. The spherical with sponge-like hexagonal structure morphologies were found for ANZ nanocomposite observed from SEM. The presence of elements such as $\mathrm{Ag}, \mathrm{Nd}, \mathrm{O}, \mathrm{Zn}$ and $\mathrm{C}$ is confirmed by EDX analysis. 
The MB was completely degraded within 30 minutes under Visible light irradiation. The ANZ nanocomposite contains superior chemical stability and good reusability for after the fifth degradation runs. And the antibacterial study, the higher activity is noticed in Bacillus bacteria by ANZ catalyst than the E.Coli bacteria.

\section{ACKNOWLEDGEMENT}

The author, M.A acknowledges Kalasalingam Academy of Research and Education for providing research fellowship and necessary facilities.

\section{REFERENCES}

[1] L.M. Pastrana-Martinez, J.L. Faria, J.M. Dona - Rodriguez, C. Fernandez-Rodriguez, A.M.T. Silva, Degradation of diphenhydramine pharmaceutical in aqueous solutions by using two highly active TiO2 photocatalysts: operating parameters and photocatalytic mechanism, Appl. Catal. B 113-114 (2012) 221-227.

[2] A.Ahmad, F.D.Daschner K. Kummerer, Biodegradability of cefotiam, ciprofloxacin, meropenem, penicillin $\mathrm{G}$, and sulfamethoxazole and inhibition of wastewater bacteria, Arch. Environ. Contam. Toxicol. 37 (1999) 158-163.

[3] M. A. Rauf, M. A. Meetani, A. Khaleel, A. Ahmed, Photocatalytic degradation of Methylene Blue using a mixed catalyst and product analysis by LC/MS, Chem. Eng. J. 2010, 157, 373-378.

[4] T. Sreethawong, S. Chavadej, S. Ngamsinlapasathian, S. Yoshikawa, Sol-gel synthesis of a mesoporous assembly of $\mathrm{Nd} 2 \mathrm{O} 3$ nanocrystals with the aid of structure-directing surfactant, Solid State Sci. 10 (2008) 20-25.

[5] R. Bazzi, M.A. Flores-Gonzalez, C. Louis, K. Lebbou, C. Dujardin, A Brenier, W. Zhang, O. Tillement, E. Bernstein, P. Perriat, Synthesis and luminescent properties of sub-5-nm lanthanide oxides nanoparticles, J. Lumin. 102 (2003) 445-450.

[6] M. Zawadzki, L. Kepin'ski, Synthesis and characterization of neodymium oxide nanoparticles, J. Alloys. Compd. 380 (2004) 255-259.

[7] T. Liu, Y. Zhang, H. Shao, X. Li, Synthesis and characteristics of Sm2O3 and Nd2O3nanoparticles, Langmuir 19 (2003) 7569-7572.

[8] U. Koch, A. Fojtik, H. Weller, A. Henglein, Photochemistry of semiconductor colloids. Preparation of extremely small $\mathrm{ZnO}$ particles, fluorescence phenomena and size quantization effects, Chem. Phys. Lett. 122 (1985) 507-510.

[9] S. Krishnamoorthy, A.A. Iliadis, T. Bei, P.G. Chrousos, An interleukin-6 $\mathrm{ZnO} / \mathrm{SiO} 2 / \mathrm{Si}$ surface acoustic wave biosensor, Biosens. Bioelectron. 24 (2008) 313-318.

[10] Y.L. Wang, H.S. Kim, D.P. Norton, S.J. Pearton, F. Ren, Dielectric passivation effects on $\mathrm{ZnO}$ light-emitting diodes, Appl. Phys. Lett. 92 (2008) 112101

[11] M. R. S. Zaidan, A. Noor Rain, A. R. Badrul, A. Adlin, A. Norazah, I. Zakiah, In vitro screening of five local medicinal plants for antibacterial activity using disc diffusion method, Tropical Biomedicine, 22, 2005, 165-170.

[12] D. Xu, Y. Bai, Z. Li, Y. Guo, L. Bai, Enhanced photodegradation ability of solvothermal synthesized metallic copper-coated $\mathrm{ZnO}$ microrods, Colloids Surf. A 548 (2018) 19-26.

[13] M. Rani, U. Shanker, Sun-light has driven rapid photocatalytic degradation of Methylene blue by poly(methyl methacrylate)/metal oxide nanocomposites, Colloids Surf. A Physicochem. Eng. Asp. 559 (2018) 136-147.

[14] F.T. Li, Y. Zhao, Q. Wang, X.J. Wang, Y.J. Hao, R.H. Liu, D.S. Zhao, Enhanced visible-light photocatalytic activity of active Al2O3/g-C3N4 heterojunctions synthesized via surface hydroxyl modification, J. Hazard.Mater. 283 (2015) 371-381.

\section{AUTHORS PROFILE}

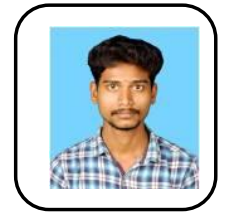

M. Arunpandian is a research scholar at Nanomateria Laboratory, Department of Chemistry, International Research Centre, Kalasalingam Academy of Research and Education (Deemed to be University), Krishnankoil, India. $\mathrm{He}$ is working in the area materials Characterization, waste water purification and Photocatalysis.

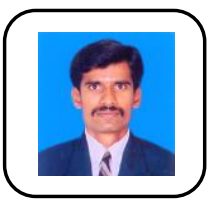

Dr. K. Selvakumar is a Postdoctoral Fellow at Nanomaterials Laboratory, Department of Chemistry, International Research Centre, Kalasalingam Academy of Research and Education (Deemed to be University), Krishnankoil, India. Now, he is working on the Postdoctoral Researcher, Institute of Microstructure and Property of Advanced Materials, Beijing University of Technology, Ping Le Yuan, Chaoyang, Beijing, China. He has published 21 papers in peer-reviewed journal on the kinetics, organic synthesis and photocatalysis.

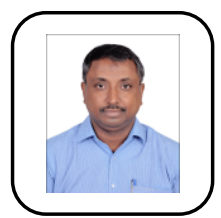

Dr. E. R. Nagarajan is Assistant Professor in Department of Chemistry, International Research Centre, Kalasalingam Academy of Research and Education (Deemed to be University), Krishnankoil, India. His area of research is Inorganic and Polymeric chemistry, Nanomaterials, Photocatalysis.

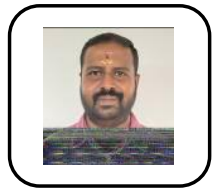

Dr. S. Arunachalam is Assistant Professor in Department of Chemistry, International Research Centre, Kalasalingam Academy of Research and Education (Deemed to be University), Krishnankoil, India. His area of Research is Inorganic and Bio-inorganic chemistry, Photocatalysis, etc., 